\title{
Hostile interaction in a general hospital ward leading to disturbed behaviour and bulimia in anorexia nervosa: its successful management
}

\author{
SAMUEl I. COHEN \\ B.Sc., M.D., F.R.C.P., F.R.C.Psych. \\ The London Hospital, London E1 1BB
}

\begin{abstract}
Summary
A girl of 17 years with severe anorexia nervosa, treated on a medical ward in a teaching hospital, developed bulimia, stole food, was sometimes doubly incontinent, behaved angrily, and aroused the hostility of patients and staff. The growth of a vicious circle of hostility is described and it was hypothesized that the hostility had aggravated the bulimia. On the basis of this hypothesis the situation was clarified with the patient and staff, attitudes changed, the patient's appetite dropped within a day from about six times to one-and-a-half times the normal and her behaviour became normal. The significance of these events is briefly discussed.
\end{abstract}

\section{Introduction}

The idea of the 'Therapeutic Community' has come to dominate most of our psychiatric hospitals. The freeing and encouragement of communication at all levels has immeasurably improved the atmosphere in these hospitals and the effect on the patient's symptoms and on the time he spends in hospital has been dramatic.

The application of these ideas in the general hospital has been much more limited. In 1962 Revans reported his investigations of fifteen hospitals in the North of England. He estimated statistically, using various measures, the freedom of communication between the sisters and the senior medical and nursing staff, and between the sisters and the junior nurses. He showed that those hospitals with a good communications system not only had a stable professional staff but also enabled their patients to be discharged more rapidly.

Newcomb (1947) described the vicious circle whereby hostile attitudes lead to an avoidance of communication so that the conditions necessary for the elimination of the hostile attitudes are not likely to occur, and the hostility consequently grows. In the situation to be described it is shown how the breakdown of communication and the growth of hostile attitudes on a general hospital ward led to a serious worsening of the patient's symptoms, as well as to disordered behaviour which affected the whole ward.

The patient and the problem

A 17-year-old girl suffering from anorexia nervosa was first seen in a medical ward at The London Hospital 2 years after the onset of symptoms when, she said, 'I suddenly started not wanting to eat'. When she ate she felt she had done something wrong. In this time her weight had dropped from its normal level of about $55 \mathrm{~kg}$ to about $35 \mathrm{~kg}$, and she had begun to develop oedema. Menstruation, which had previously been regular, had not occurred since the onset of the anorexia. For about one year she had been depressed, often wanting to cry, and had been irritable and unable to concentrate. She had been treated elsewhere with insulin and chlorpromazine, and her weight had risen to $46 \mathrm{~kg}$ but it had soon dropped after discharge from hospital.

At the first consultation she gave a good account of herself, though she was careful to avoid talking about feelings. She expressed considerable resentment at the treatment she had received previously, especially the insulin and chlorpromazine, and she said she did not wish to have similar treatment again. Plans were made for her admission for psychiatric treatment and for her to go home to await this. However, as she was so thin she was not discharged and her physicians decided to attempt to increase her weight using these drugs. Unfortunately, the consultant psychiatrist (S.I.C.) was not informed - the first breakdown in communication. Twelve units of insulin were given before the evening meal and it was noted the next morning that she was behaving strangely. Her behaviour was thought to be 'hysterical', and no action was taken. A further twelve units were given before her lunch, and by the late afternoon she was unconscious with a blood sugar level of $12 \mathrm{mg} / 100 \mathrm{ml}$. Treatment with glucose was given, first intravenously and then by mouth and consciousness rapidly returned although there remained some clouding of consciousness for 36-48 $\mathrm{hr}$. In the succeeding two weeks she was at times mute. Sometimes she asked for food, and at other times she refused it. She was often incontinent of urine and faeces and at times played with and ate her faeces, although at times she walked about the ward and conversed normally. During this time she was fed largely by tube, although she frequently pulled this out. She took very little solid food, but on occasion said she would like 'a full course meal' - though she 
does not seem to have been given one and at the time she said this she was being fed by tube. During this time her weight rose a little. She then began to eat excessively and greedily and to behave aggressively towards the nurses, doctors and other patients. She stole food from the ward kitchen and from other patients, and on one occasion bit the ward sister. She continued to be incontinent of urine and faeces although she was quite alert. She put on $18 \mathrm{~kg}$ in weight. Her consumption of food was approximately six times that of the average patient, and it included large quantities of chocolates and sweets which she bought from the travelling shop. Restrictions had been placed upon the quantity she was allowed to buy, and other attempts had been made to restrict her intake of food, at meals and between them.

The consultant was asked to see her again after she had been behaving like this for about two weeks. She was alert and orientated, and her behaviour was bitterly hostile and sullen. After a few minutes she asked to leave the consulting room in order to go to the toilet. The consultant said that she could go but that he did not think that that was really why she wanted to go and that she was obviously very angry. When she did not return after about 5 minutes he went into the ward and found her in the ward kitchen having an acrimonious argument with a wardorderly who was attempting to limit the number of slices of bread she could have for tea, which was then being served. She was told by the consultant to take whatever she wished and to bring it into the consulting room. She did this, and sat munching her way ferociously through a large number of slices of bread and butter and jam. She answered questions in an off-hand way. When she had finished the bread she ate the jam on the side of her plate by dipping in her finger and licking it, at the same time scowling angrily at the consultant, obviously trying to make him angry with her.

He interpreted to her that she was very angry with him and with all her doctors and nurses and that she was trying to make him angry with her.

\section{The vicious circle of hostility}

The consultant thought she was feeling very angry at the way she had been treated - at being given the chlorpromazine and insulin, at being fed by tube, at not being given whatever food she requested and at the restrictions that had been placed on her purchase of food, whereas only a few weeks before great efforts had been made to coax her to eat. He thought her anger had led to her aggressive behaviour on the ward and this in turn had provoked hostility in the staff. There seemed to be no other good reason why her intake of food had been restricted, nor why she was fed by tube for a considerable time after it was no longer medically necessary. A vicious circle had been set up with hostility breeding hostility, and this had spread even as far as the ward-orderly. Whereas the refusal to eat could be considered to be aggression which was directed inwardly, the gross overeating was aggression directed outwardly. Whether the change from anorexia to bulimia was a spontaneous change in the illness, a physical reaction to hypoglycaemia, a result of her anger at being treated with insulin and chlorpromazine, or a combination of these, it appeared that as she became more angry so did her intake of food increase. If this hypothesis were correct one might expect her appetite to be reduced very considerably if this vicious circle of hostility could be interrupted by a suitable intervention.

\section{The intervention}

The consultant told the patient that he could not understand why she had been treated in this way, when she so obviously wanted to eat, that he could understand why she felt angry, and that he would discuss matters with her doctor and nurses. When he did so it was obvious that they were angry with her, and felt guilty at their anger. He described to them how she had behaved with him and that this had made him feel angry and he told them he thought itwould have been very unusual if they had not felt angry in the circumstances. They were greatly relieved by this. They said that she had bought twenty bars of chocolate from the shop on one occasion, and that this was why her access to the shop was being restricted, but there seemed to be no real reason why she had been fed by tube for so long. It was pointed out to them that the worst that could happen if she ate all the chocolate was that she would vomit, and they agreed that the restrictions did not seem to have any purpose and had really been imposed because they were angry. The consultant explained to them how the vicious circle described above had arisen. All agreed that all restrictions would be lifted, and they felt that they would be able to deal with her more sympathetically from then on. He told the patient he had discussed things with the staff and that she could buy and eat whatever she wished.

\section{The outcome}

By the next day her appetite had dropped from about six times to about one-and-a-half times the normal, and when the travelling shop came to the ward she did not wish to buy anything. Her stealing, aggressive behaviour and incontinence ceased in the ensuing few days. This outcome confirmed the correctness of the formulation on which the intervention had been based.

These interviews with the patient and staff took 
about 2 hours and brought to an end a disturbance which had lasted for 2 weeks and which had involved many people.

\section{Discussion}

The response to a stimulus must depend upon the level of the subject's arousal at the time it is applied. An excited person will not sleep with a dose of sedative which would otherwise be adequate for him and the nervous person will be the first to cough in a smoky atmosphere. Twycross (1975) in discussing the relief of terminal pain, describes how symptoms tend to multiply and worsen as resentment builds up and how a group of general practitioners found that they could reduce drugs as the doctor-patient relationship improved. The author has described how relief from asthma and a reduced need for drugs can follow the resolution of tension between the doctor and the patient (Cohen, 1977).
In the case reported here, neither patient, doctors nor nurses were clearly aware of the reasons for their hostile behaviour. Because of the breakdown in communication there was no way to eliminate the hostile attitudes. When the reasons for the behaviour were clarified it ceased, and the patient's symptoms improved. The situation described illustrates the importance of understanding such behaviour not as originating exclusively from the individual but as the result of interaction within his group.

\section{References}

Cohen, Samuel I. (1977) Asthma (Ed. by Clark, T.J.H. \& Godfrey, S.), p. 186. Chapman \& Hall, London.

Newcomb, T.M. (1947) Autistic hostility and social reality. Human Relations, 1, 69.

Revans, R.W. (1962) Hospital Attitudes and Communications. Sociological Review: Monograph No. 5, 117.

TwyCRoss, R.G. (1975) Diseases of the central nervous system. Relief of terminal pain. British Medical Journal, 4, 212. 